\title{
Use of Water Isotopes in Hydrological Processes
}

\author{
Polona Vreča ${ }^{1, *(\mathbb{D})}$ and Zoltán Kern ${ }^{2, * \text { (D) }}$ \\ 1 Department of Environmental Sciences, Jožef Stefan Institute, Jamova cesta 39, 1000 Ljubljana, Slovenia \\ 2 Institute for Geological and Geochemical Research, Research Centre for Astronomy and Earth Sciences, \\ MTA Centre for Excellence, Budaörsi út 45, H-1112 Budapest, Hungary \\ * Correspondence: polona.vreca@ijs.si (P.V.); zoltan.kern@gmail.com (Z.K.)
}

Received: 25 July 2020; Accepted: 6 August 2020; Published: 7 August 2020

\begin{abstract}
Stable $\left({ }^{16} \mathrm{O},{ }^{17} \mathrm{O},{ }^{18} \mathrm{O},{ }^{1} \mathrm{H},{ }^{2} \mathrm{H}\right)$ and radioactive $\left({ }^{3} \mathrm{H}\right)$ isotopes in water are powerful tools in the tracking of the path of water molecules in the whole water cycle. In the last decade, a considerable number of studies have been published on the use of water isotopes, and the number continues to grow due to the development of new measurement techniques (i.e., laser absorption spectroscopy) that allow measurements of stable isotope ratios at ever-higher resolutions. Therefore, this Special Issue (SI) has been compiled to address current state-of-the-art water isotope methods, applications, and hydrological process interpretations and to contribute to the rapidly growing repository of isotope data important for future water resource management. We are pleased to present here a compilation of 14 papers reporting the use of water isotopes in the study of hydrological processes worldwide, including studies on the local and regional scales related either to precipitation dynamics or to different applications of water isotopes in combination with other hydrochemical parameters in investigations of surface water, snowmelt, soil water, groundwater, and xylem water to identify the hydrological and geochemical processes.
\end{abstract}

Keywords: water cycle; isotope hydrology; measurement traceability; precipitation (rain and snow); surface water; groundwater; water management; networks and data bases; statistical evaluation

\section{Introduction}

Water is vital for all known forms of life and is transported continuously through the different spheres of Earth in the water cycle: evaporation, transpiration, condensation, precipitation, runoff, infiltration, etc. As such, fresh water plays an important role in the world economy as well. Since ancient times, cities have been built around reliable sources of water, and a considerable amount of the total available fresh water is used for irrigation and other agricultural activities to supply humanity with sustenance.

Stable $\left({ }^{16} \mathrm{O},{ }^{17} \mathrm{O},{ }^{18} \mathrm{O},{ }^{1} \mathrm{H},{ }^{2} \mathrm{H}\right)$ and radioactive $\left({ }^{3} \mathrm{H}\right)$ isotopes in water molecules are powerful tools for the tracking of the path of water molecules in the water cycle, from precipitation to surface and groundwater, and further, into the drinking water supply. They are commonly used to trace the source of water and its flow pathways, or to quantify exchanges of water, solutes, and particulates between hydrological compartments during different hydrological processes [1].

In the last decade, a considerable number of studies have been published on the use of water isotopes in hydrological processes, and their number is ever-growing. The main reason is due to the development of new measurement techniques (i.e., tunable diode isotope ratio infrared laser absorption spectroscopy - LAS) that have been increasingly employed in hydrological studies since 2007, and allow measurements of stable isotope ratios with much smaller sample sizes [2,3]. In the last few years, Water MDPI has published fifty-four papers related to the application of water isotopes, and an exponentially increasing trend can be observed with time: 2016-4 papers; 2017-6; 2018-12; 
2019-24. Most of the papers were published in the framework of the three closed Special Issues (SI), namely "Isotopes in Hydrology and Hydrogeology" (20 papers), "Advances in Isotope Tracer Techniques for Tracing and Quantifying Hydrological Processes" (4 papers), and "Radioactive Isotopes in Hydrosphere" (4 papers).

To continue, the SI "Use of Water Isotopes in Hydrological Processes" addresses the current state-of-the-art methods, applications, and hydrological process interpretations using stable and radioactive water isotopes in the whole water cycle. In addition, accurate and precise measurements are required [3] to provide new data comparable in space and time, or comparable with data obtained with classical isotope ratio mass spectrometry (IRMS) [4]. Therefore, contributions related to some specific topics, such as measurement traceability (comparison of different measurement techniques), conceptual network development, and long-term maintenance of networks on the local to regional scale, as well as papers on different statistical data evaluation approaches, were also given a warm welcome in this SI. The SI was first announced in January 2019, and an invitation was sent to researchers through different channels. The first paper was submitted in March 2019 and the last in April 2020. In total, 18 submissions were received, and following a rigorous peer-review process carried out by qualified reviewers, one review and 13 research papers were selected for publication.

\section{Contributions}

In the following, we briefly present an overview of fourteen papers published in the period April 2019 to June 2020 [5-18]. The overview shows that contributions can be divided into two groups: the first related to isotopes in precipitation, and the second related to more complex hydrological and hydrogeological investigations. It is interesting that all contributions report on isotopes in precipitation, and five of them $[6,7,11,14,18]$ focus in greater detail on isotopes in precipitation monitoring networks with longer and continuous observations. The importance of isotopes in precipitation data is understandable, as precipitation represents an important part of the water cycle and is the ultimate source of water to catchments. Other papers report on the use of precipitation isotope data as part of more complex hydrological and hydrogeological investigations [5,8-10,12,13,15-17]. Those papers report on different isotope sampling networks, including the collection and evaluation of precipitation, surface, and groundwater data. In some studies, also other samples like snow, ice, or snowmelt [10,12], soil water [13,17], or xylem water [13] were also collected.

The compilation of papers in this SI represents a variety of studies with a global scope. The only review paper in the SI discusses the combined use of stable isotopes of water and nitrate, and focuses on the fundamental background, analytical methods, and hydrograph separation, and reports perspectives related to quantification of relative nitrate contributions to stream water contamination [5].

Other papers present case studies with sampling performed either at a particular location [14,17], or within a research area from a few $\mathrm{m}^{2}[13]$ to a few tens of $\mathrm{km}^{2}[8,10,15,16]$, or on a larger regional scale of more than $1000 \mathrm{~km}^{2}[9,12,18]$. A few papers focus on the evaluation of published data sets for particular countries, e.g., Chile [6], China [7], or Iran [11].

Further, the isotope measurements discussed herein were performed using either IRMS [8,9] or LAS $[10,12,13,15-17]$. Some papers combine or evaluate data obtained using different techniques [5-7, $11,14,18]$. Although authors usually report details of the instruments used and the degree of analytical precision, it must be admitted that it is not always clear how the calibration of the instrument and normalization of the data are performed [19], nor always how the reported degree of precision was determined. Terminology that was often not in line with the IUPAC recommendations is also an occasional issue [20], though this deficiency was improved during the peer-review process.

An important and valuable contribution of some papers is the supplementary material $[6,9-11,14$, $17,18]$, with "raw" data and detailed explanations that enable better use of isotope data in future water resources research and management, in line with FAIR data practice [21]. 


\subsection{Isotopes in Precipitation}

All papers in this SI report information on the isotope composition of precipitation. In this section, we focus on those dedicated only to precipitation monitoring, the establishment of local meteoric water lines (LMWL) with the use of different regression models, and those related to precipitation dynamics $[6,7,11,14,18]$.

Boschetti et al. [6] collected isotope data from 32 stations in Chile from different sources, and calculated the LMWL with a confidence interval for this region arrived at by introducing a technique known as error-in variables (EIV) regression. The slopes obtained either using EIV or ordinary last square regression (OLSR) are similar. However, according to authors' conclusions, the new EIV-LMWL is more accurate and suitable than the OLRS or other types of regression models where the measurement errors in the $x$-axis are violated.

Kong et al. [7] present a meta-analysis of precipitation isotopes by using data from 68 stations from in and around China from different sources. They divided the entire country into five regions according to their major moisture sources, and determined the spatial distribution and seasonal variations of the isotope composition of precipitation. The LMWLs were then calculated for each region by applying the OLRS model on the basis of monthly data. The $\delta^{18} \mathrm{O}$-temperature and the $\delta^{18} \mathrm{O}$-precipitation amount gradients for the regions were also determined. The conclusion was that the findings could serve as a reference for isotopic application in hydrological and paleo-climate research.

Heydarizad et al. [11] collected isotope data from different sources for 32 stations in Iran and 4 from Iraq and developed three different LMWLs for Iran by applying the OLRS and considering air masses and dominant moisture sources in the particular region. They validated the LMWL by comparison with fresh karstic spring and surface water isotope data from across Iran and determined the main moisture sources important for those water resources.

In contrast to previous papers, Krajcar Bronić et al. [14] focused on a long-term isotope record of precipitation at one station, namely Zagreb in Croatia. The history of isotope monitoring performed since 1976 is described in detail, and in addition to stable isotope data, tritium activity concentration together with air temperature and precipitation amount are reported. A statistical evaluation of the data showed a significant increase in the annual air temperature and larger variations in that of the amount of precipitation, in addition to an increase in the annual $\delta^{18} \mathrm{O}$ and the $\delta^{2} \mathrm{H}$ values and a slight decrease in tritium activity concentration over the last two decades. The LMWL was calculated using different regression models proposed by Crawford et al. [22], and did not result in significant differences.

The last paper in this group evaluates the results of a three-year program monitoring the stable isotope composition of precipitation in the Adriatic-Pannonian region; it focuses on the determination of the isotopic "altitude" and "continental" effects in this particular region [18]. Isotope data were collected from 15 stations ( 5 in Hungary, 7 in Slovenia, 2 in Austria, and 1 in Croatia). On the basis of the isotope data obtained, an "altitude" effect of $-1.2 \% \mathrm{o} / \mathrm{km}$ for $\delta^{18} \mathrm{O}$ and $-7.9 \% \mathrm{o} / \mathrm{km}$ for $\delta^{2} \mathrm{H}$ was calculated-and it is recommended that this figure be used for modern precipitation in the region. The estimated mean isotopic "continental" effect could, however, only be determined for the winter precipitation, and figures of $-2.4 \% / 100 \mathrm{~km}$ in $\delta^{18} \mathrm{O}$ and $-20 \% \mathrm{o} / 100 \mathrm{~km}$ in $\delta^{2} \mathrm{H}$ were arrived at. The authors conclude that the isotopic "altitude" and "continental" effects thus determined can be used in future isotope hydrological or paleoclimatological applications in the Adriatic-Pannonian region.

\subsection{Use of Water Isotopes in Complex Investigations}

In this section, we briefly summarize the most important outcomes of other papers reporting on the use of water isotopes in complex hydrological and hydrogeological investigations [8-10,12,13,15-17].

Porowski et al. [8] studied the sources and biogeochemical processes in an aquifer affected by peatland in Kampinos National Park in Poland. Using a combination of chemical and isotopic data, they were able to determine the main sources of the sulfates dissolved in groundwater. The atmospheric sulfates, that is, sulfates formed by the dissolution of evaporate sulfate minerals and sulfates formed 
by oxidation of pyrite, were also identified. In this paper, water isotopes were used to identify the atmospheric inputs and the groundwater recharge.

Van Lam et al. [9] used different isotope techniques in investigations of groundwater resources of the delta plain of the Red River in Vietnam. The authors carried out short-term observations of local precipitation and used the precipitation water isotope data to determine the LMWL by applying the OLSR. Further, they determined the isotope composition of surface water, groundwater, and sea water, and studied the genesis of and processes controlling the quality of water resources in the region. They also determined the influence of salt water intrusions and studied the connection between different aquifers.

Sing et al. [10] applied water isotope investigations to the Sutri Dhaka glacier basin in the Himalayas, where they established a short-term observation site with the sampling of rain, snow, ice, and snowmelt water. The authors used the precipitation data to determine the moisture sources and LMWL, though they do not report the regression method used for the calculation of lines. Further, a three-component hydrograph separation based on stable isotope methods was applied to estimate the contribution of ice-melt and snowmelt to runoff.

Chen et al. [12] used a similar approach to Sing et al. [10] in the Naqu River basin on the Qinghai-Tibet Plateau. They established a short-term sampling site at which they collected precipitation, snowmelt, and groundwater for isotope analysis to explore the sources of runoff and the spatial variation of the discharge. The authors determined the LMWL and the river water line using the linear relationship, albeit without a more specific explanation of the regression method used. Finally, they used the water isotope data for the hydrograph separation and estimated the proportion of rainwater, snowmelt, and groundwater to the runoff.

Tsuchihara et al. [15] investigated the spatial distribution of the isotopic and hydrochemical composition of groundwater in selected alluvial fans under cultivation as rice paddies in Japan. They used an unsupervised training algorithm of an artificial neural network model developed by Kohonen [23] and applied a self-organizing map (SOM) to characterize the spatial pattern of groundwater hydrochemistry. With the use of the SOM, the groundwater could clearly be classified into four groups, and the different origins of water identified. Their findings represent an important contribution to the proper management of groundwater resources. The systematic, well-organized sampling approach, the data evaluation used, and the outcomes of Tsuchihara et al. [15] are to be recommended as an interesting approach in the future management of water resources.

Marković et al. [16] focused on the application of stable isotopes in combination with hydrochemical parameters for the improvement of the conceptual model of an alluvial aquifer in Croatia, which represents an important source of drinking water in the area studied. The authors used different regression models proposed by Crawford et al. [22] to calculate the LMWL for the area and, as was also the case with Krajcar Bronić et al. [14], no significant differences were observed. The authors also used the water isotope data in combination with water head data to determine the groundwater flow direction.

Jiménez-Rodríguez et al. [13] applied water isotopes to study the effect of willow plantations on soil water conditions in an arid environment in northern China. The authors discuss the influence of afforestation using different species, namely willow bushes and willow trees, and use water isotopes monitored in precipitation, soil water, groundwater, and xylem water to investigate the redistribution of water in the soil. They conclude that both species reduced the effects of soil evaporation after summer. However, the willow bush is capable of extracting soil and groundwater in different proportions according to water availability, while the willow tree is able to extract water and groundwater in specific proportions. Therefore, the selection of species for afforestation programs has to be carried out carefully, not to endanger the scarce water resources in arid regions.

The last paper in this section was contributed by Mattei et al. [17], who investigated the potential of pore water isotope information to parameterize soil water transport models. By conducting a Morris and Sobol sensitivity analysis, they were able to highlight the value of combining water content 
and pore water isotope composition data in a multi-objective calibration approach to constrain soil hydraulic property parameterization. They tested the model with pore water data collected from sandy soil at two sampling sites close to Montreal, Canada. After employing the model in order to estimate the annual groundwater recharge, they conclude that it is possible to calibrate the model without continuous monitoring data, using only water content and pore water isotopic data from a single sampling. The results presented imply the possibility of reducing long-term monitoring observations and to adapt the sampling according to the objectives of the groundwater recharge investigations.

\section{Conclusions}

Understanding water exchange within geospheres is vital if we are to address environmental issues linked to water resources management effectively. Isotopes in the water molecule determined in different compartments of the water cycle serve as natural fingerprints and allow us to trace the molecule through the water cycle. This Special Issue is dedicated to the use of water isotopes in hydrological processes and compiles new findings in selected thirteen original research papers and one review paper. All presentations report on isotopes of precipitation, either in detail or as a part of more complex case studies of water resources. Some authors discuss also the multi-parameter approach and combine the isotope and other geochemical parameters to address the specific questions. The best example of the latter is the self-organizing map approach presented by Tsuchihara et al. [15].

Few issues remain challenging for the future, e.g., the use of the appropriate terminology, the improvement of the traceability of water isotope data to provide results comparable in space and time, the reporting of the "raw" data and detailed explanations in line with FAIR data practice, and greater precision in the reporting of the sources of reused isotope data. These issues comprise, suitably, the themes of forthcoming Water MDPI Special Issues, "Application of Stable Isotopes and Tritium in Hydrology", "Isotope Hydrology", "Application of Isotopic Data to Water Resource Management", "Geochemistry of Groundwater", and "Applying Artificial and Environmental Tracing Techniques in Hydrogeology".

The Guest Editors of this SI are also considering a sequel to follow up the achievements of this SI, to be entitled "Use of Water Isotopes in Hydrological Processes, part II" in 2021. In addition, such an SI could cover the focus areas of a recently started COST Action "WATer isotopeS in the critical zONe: from groundwater recharge to plant transpiration (WATSON)", CA19120, a compilation in the recent SI which may be considered an inspiration to the working groups in the Action.

Author Contributions: Conceptualization, P.V.; formal analysis, P.V. and Z.K.; writing, reviewing and editing, P.V. and Z.K.; funding acquisition, P.V. and Z.K. All authors have read and agreed to the published version of the manuscript.

Funding: The Guest Editors activities for this Special Issue were supported by the National Research, Development and Innovation Office under Grants SNN118205 and by the Slovenian Research Agency ARRS under Grants N1-0054, J4-8216 and P1-0143.

Acknowledgments: The Guest Editors express their gratitude to the Water MDPI in-house editors for their valuable help during the processing of the manuscripts. We also thank the researchers for contributing their findings and all the reviewers for their valuable comments that have greatly improved the outcome of the SI.

Conflicts of Interest: The authors declare no conflict of interest.

\section{References}

1. Aggarwal, P.K.; Froehlich, K.F.; Gat, J.R. Isotopes in the Water Cycle; Springer: Dordrecht, The Netherlands, 2005 ; p. 382.

2. Lis, G.; Wassenaar, L.I.; Hendry, M.J. High-Precision Laser Spectroscopy D/H and ${ }^{18} \mathrm{O} /{ }^{16} \mathrm{O}$ Measurements of Microliter Natural Water Samples. Anal. Chem. 2008, 80, 287-293. [CrossRef] [PubMed]

3. Wassenaar, L.I.; Coplen, T.B.; Aggarwal, P.K. Approaches for Achieving Long-Term Accuracy and Precision of $\delta^{18} \mathrm{O}$ and $\delta^{2} \mathrm{H}$ for Waters Analyzed using Laser Absorption Spectrometers. Environ. Sci. Technol. 2014, 48, 1123-1131. [CrossRef] [PubMed] 
4. Wassenaar, L.I.; Terzer-Wassmuth, S.; Douence, C.; Araguas-Araguas, L.; Aggarwal, P.K.; Coplen, T.B. Seeking excellence: An evaluation of 235 international laboratories conducting water isotope analyses by isotope-ratio and laser-absorption spectrometry. Rapid. Commun. Mass. Spectrom. 2018, 32, 393-406. [CrossRef]

5. Jung, H.; Koh, D.-C.; Kim, Y.S.; Jeen, S.-W.; Lee, J. Stable Isotopes of Water and Nitrate for the Identification of Groundwater Flowpaths: A Review. Water 2020, 12, 138. [CrossRef]

6. Boschetti, T.; Cifuentes, J.; Iacumin, P.; Selmo, E. Local Meteoric Water Line of Northern Chile $\left(18^{\circ} \mathrm{S}-30^{\circ}\right.$ S): An Application of Error-in-Variables Regression to the Oxygen and Hydrogen Stable Isotope Ratio of Precipitation. Water 2019, 11, 791. [CrossRef]

7. Kong, Y.; Wang, K.; Li, J.; Pang, Z. Stable Isotopes of Precipitation in China: A Consideration of Moisture Sources. Water 2019, 11, 1239. [CrossRef]

8. Porowski, A.; Porowska, D.; Halas, S. Identification of Sulfate Sources and Biogeochemical Processes in an Aquifer Affected by Peatland: Insights from Monitoring the Isotopic Composition of Groundwater Sulfate in Kampinos National Park, Poland. Water 2019, 11, 1388. [CrossRef]

9. Van Lam, N.; Van Hoan, H.; Duc Nhan, D. Investigation into Groundwater Resources in Southern Part of the Red River's Delta Plain, Vietnam by the Use of Isotopic Techniques. Water 2019, 11, 2120. [CrossRef]

10. Singh, A.T.; Rahaman, W.; Sharma, P.; Laluraj, C.M.; Patel, L.K.; Pratap, B.; Gaddam, V.K.; Thamban, M. Moisture Sources for Precipitation and Hydrograph Components of the Sutri Dhaka Glacier Basin, Western Himalayas. Water 2019, 11, 2242. [CrossRef]

11. Heydarizad, M.; Raeisi, E.; Sorí, R.; Gimeno, L. Developing Meteoric Water Lines for Iran Based on Air Masses and Moisture Sources. Water 2019, 11, 2359. [CrossRef]

12. Chen, X.; Wang, G.; Wang, F.; Yan, D.; Zhao, H. Characteristics of Water Isotopes and Water Source Identification During the Wet Season in Naqu River Basin, Qinghai-Tibet Plateau. Water 2019, 11, 2418. [CrossRef]

13. Jiménez-Rodríguez, C.D.; Coenders-Gerrits, M.; Uhlenbrook, S.; Wenninger, J. What Do Plants Leave after Summer on the Ground?-The Effect of Afforested Plants in Arid Environments. Water 2019, 11, 2559. [CrossRef]

14. Krajcar Bronić, I.; Barešić, J.; Borković, D.; Sironić, A.; Mikelić, I.L.; Vreča, P. Long-Term Isotope Records of Precipitation in Zagreb, Croatia. Water 2020, 12, 226. [CrossRef]

15. Tsuchihara, T.; Shirahata, K.; Ishida, S.; Yoshimoto, S. Application of a Self-Organizing Map of Isotopic and Chemical Data for the Identification of Groundwater Recharge Sources in Nasunogahara Alluvial Fan, Japan. Water 2020, 12, 278. [CrossRef]

16. Marković, T.; Karlović, I.; Perčec Tadić, M.; Larva, O. Application of Stable Water Isotopes to Improve Conceptual Model of Alluvial Aquifer in the Varaždin Area. Water 2020, 12, 379. [CrossRef]

17. Mattei, A.; Goblet, P.; Barbecot, F.; Guillon, S.; Coquet, Y.; Wang, S. Can Soil Hydraulic Parameters Be Estimated from the Stable Isotope Composition of Pore Water from a Single Soil Profile? Water 2020, 12, 393. [CrossRef]

18. Kern, Z.; Hatvani, I.G.; Czuppon, G.; Fórizs, I.; Erdélyi, D.; Kanduč, T.; Palcsu, L.; Vreča, P. Isotopic 'Altitude' and 'Continental' Effects in Modern Precipitation across the Adriatic-Pannonian Region. Water 2020, 12, 1797. [CrossRef]

19. Paul, D.; Skrzypek, G.; Fórizs, I. Normalization of measured stable isotopic compositions to isotope reference scales -a review. Rapid Commun. Mass Spectrom. 2007, 21, 3006-3014. [CrossRef]

20. Coplen, T.B. Guidelines and recommended terms for expression of stable-isotope-ratio and gas-ratio measurement results: Guidelines and recommended terms for expressing stable isotope results. Rapid Commun. Mass Spectrom. 2011, 25, 2538-2560. [CrossRef]

21. Stall, S.; Yarmey, L.; Cutcher-Gershenfeld, J.; Hanson, B.; Lehnert, K.; Nosek, B.; Parsons, M.; Robinson, E.; Wyborn, L. Make scientific data FAIR. Nature 2019, 570, 27-29. [CrossRef]

22. Crawford, J.; Hughes, C.E.; Lykoudis, S. Alternative least squares methods for determining the meteoric water line, demonstrated using GNIP data. J. Hydrol. 2014, 519, 2331-2340. [CrossRef]

23. Kohonen, T. Self-organized formation of topologically correct feature maps. Biol. Cybern. 1982, 43, 59-69. [CrossRef]

(C) 2020 by the authors. Licensee MDPI, Basel, Switzerland. This article is an open access article distributed under the terms and conditions of the Creative Commons Attribution (CC BY) license (http://creativecommons.org/licenses/by/4.0/). 